\title{
Inhibition of Oxidative Stress in Brain During Rat Adjuvant Arthritis by Carnosine, Trolox and Novel Trolox-Carnosine
}

\author{
S. PONIŠT ${ }^{1}$, L. SLOVÁK ${ }^{1}$, V. KUNCÍROVÁ ${ }^{1}$, T. FEDOROVA ${ }^{2}$, A. LOGVINENKO ${ }^{2}$, \\ O. MUZYCHUK ${ }^{2}$, D. MIHALOVÁ ${ }^{1}$, K. BAUEROVÁ ${ }^{1}$ \\ ${ }^{1}$ Institute of Experimental Pharmacology and Toxicology of Slovak Academy of Sciences, \\ Bratislava, Slovak Republic, ${ }^{2}$ Research Center of Neurology, Moscow, Russian Federation
}

Received September 16, 2015

Accepted October 2, 2015

\section{Summary}

Carnosine (CARN) is an anti-glycating agent able to quench superoxide, and to neutralize 4-hydroxynonenal. Trolox-carnosine (CARN-T) was synthesized because of its resistance against degradation and to improve CARN antioxidant capacity. We evaluated the impact of trolox (TRO), CARN and its derivative CARN-T on oxidative stress (OS) in brain during rat adjuvant arthritis (AA). The experiments were done on healthy, control arthritic and arthritic animals with administration of CARN 150 mg/kg b.w., TRO 41 mg/kg b.w. and CARN-T 75 mg/kg b.w. in a daily dose during 28 days. Antioxidants did not affect the body weight on day 14 , but on day 28 TRO enhanced the weight reduction. On day 14 and 28 CARN-T and TRO reduced arthritic score. IL-1beta, MCP-1 and MMP-9 were measured in plasma on day 14. MCP-1 was decreased by CARN-T and TRO. All antioxidants reduced IL-1beta and MMP-9 levels. Malondialdehyde, 4-hydroxynonenal and protein carbonyls were increased in brain. CARN, CARN-T and TRO prevented higher lipid and protein oxidation in brain. CARN and CARN-T caused no weight reduction like TRO that has an advantage in inflammatory arthritis. Moreover the antioxidants administered had a similar therapeutic effects on arthritic score, markers of inflammation in plasma and OS in brain.

\section{Key words}

Trolox-carnosine $\bullet$ Arthritis $\bullet$ Brain $\bullet$ Oxidative stress $\bullet$ Carnosine

\section{Corresponding author}

K. Bauerová, Institute of Experimental Pharmacology and Toxicology, Slovak Academy of Sciences, Dubravska cesta 9, Bratislava, Slovak Republic. E-mail: katarina.bauerova@savba.sk

\section{Introduction}

Carnosine (CARN) is dipeptide consisting of $\beta$-alanine and L-histidine. It was shown to be a specific constituent of excitable tissues of all vertebrates accumulating in amounts exceeding that of ATP (Boldyrev and Severin 1990). The antioxidant capacity of this compound is well documented, as well as its $\mathrm{pH}$ buffering, osmoregulating, and metal-chelating abilities (Boldyrev 1990). We previously showed inhibitory properties of CARN against degradation of hyaluronan solutions at experimental conditions in vitro. In the reaction system with the prevalence of $\cdot \mathrm{OH}$ and/or peroxy-type radicals, CARN in $200 \mu \mathrm{mol} / 1$ concentration tested exerted a protective action on hyaluronan degradation (Drafi et al. 2010). A potentially useful characteristic of CARN is its ability to act as an antiglycating agent (Hipkiss and Brownson 2000), to quench superoxide anion and hydroxide radical (Rubtsov et al. 1991, Pavlov et al. 1993), and to neutralize 4-hydroxynonenal (HNE) and other toxic aldehydes (Aldini et al. 2002). Trolox (TRO) - a water-soluble analog of vitamin $\mathrm{E}$ is used in biological applications to reduce oxidative stress or damage and was selected for addition with CARN. Trolox-carnosine (CARN-T) was synthesized because of its resistance against degradation by carnosinase and to improve its antioxidant capacity. CARN-T improved the long-term memory and unlike carnosine may increase the life span of both male and female fruit flies (Stvolinsky et al. 2012). At the same time, CARN-T is more stable against human serum carnosinase attack and may circulate longer in the blood 
stream (Stvolinsky et al. 2010). In combination with its more hydrophobic nature one can expect that CARN-T possibly can more easily penetrate the membrane barrier and to be more potent as a membrane protector and antistressing agent compared to carnosine.

The aim of this study was to evaluate the therapeutic potential of antioxidants, i.e. trolox, carnosine, and its acylated derivative - trolox-carnosine in rat adjuvant arthritis and their ability to prevent brain tissue from oxidative stress.

\section{Methods}

\section{Animal protocol}

Adult male Lewis rats weighing 160-180 g were obtained from Breeding Farm Dobra Voda (Slovakia). The rats had free access to standard pellet diet and tap water. The experimental protocol was approved by the Ethics Committee of the Institute of Experimental Pharmacology and Toxicology and by the Slovak State Veterinary and Food Administration in accordance with the European Convention for the Protection of Vertebrate Animals Used for Experimental and Other Scientific Purposes and with Slovak legislation. AA was induced by a single intradermal injection of heat-inactivated Mycobacterium butyricum in incomplete Freund's adjuvant (Difco Laboratories, Detroit, MI, USA) near the tail base (Bauerova et al. 2011a,b). Rats were randomized into five groups (in each group 8 animals): $\mathrm{CO}$ - healthy animals not treated, AA - untreated adjuvant-induced arthritis group, arthritic groups treated by: carnosine (CARN) $150 \mathrm{mg} / \mathrm{kg}$ b.w., trolox (TRO) $41 \mathrm{mg} / \mathrm{kg}$ b.w. and trolox-carnosine (CARN-T) $75 \mathrm{mg} / \mathrm{kg}$ b.w. in a daily oral dose during 28 days. Body weight of rats was regularly measured before each administration of substances to calculate the precise application doses. During experiment on day 14 blood samples were withdrawn from retroorbital plexus under Zoletil $^{\circledR} /$ xylasine anesthesia. After the animals were sacrificed, blood for plasma preparation and brain was taken at the end of the experiment (day 28). All plasmatic samples were stored at $-80{ }^{\circ} \mathrm{C}$ until biochemical analysis.

\section{Clinical parameters: arthritic score and body weight}

The arthritic score was measured as the total score of hind paw volume ( $\mathrm{ml}$, max. points 8 ) plus paw diameter of forelimb (mm, max. points 5) plus diameter of scab in the site of Mycobacterium butyricum application, measured parallel to the spinal column (mm, max. points 5) for each animal (Kuncirova et al. 2014). Change of body weight (CBW; g) was measured on days 1, 14 and 28. CBW was calculated as the difference of the body mass measured on days 14 and 28 and the body weight measured at the beginning of the experiment (day 1).

Measurement of monocyte chemotactic protein-1 (MCP-1), interleukin $1 \beta \quad(I L-1 \beta)$ and matrix metalloproteinase 9 (MMP-9) in plasma

For determination of MCP-1, IL-1 $\beta$ and MMP-9 concentration in plasma, ELISA kits from eBioscience ${ }^{\circledR}$ were used. Assay procedures were applied as described in the product manual. Measured rat protein present in the samples binds to anti-rat chemokine antibodies adsorbed to the microwells. The reaction of secondary biotinconjugated anti-rat chemokine antibody was evaluated by streptavidin-HRP. Tetramethyl-benzidine reaction with HRP bound to immune complex was measured at $450 \mathrm{~nm}$ in comparison with reference wavelength $620 \mathrm{~nm}$ (microplate reader MRX II, Dynex, USA). The results were calculated from standard calibration curve on internal standards.

\section{Chemiluminescence measurement of plasma antioxidant capacity}

The method used is based on the measurement of chemiluminescence in the brain homogenates and blood plasma of experimental animals being oxidized by $\mathrm{Fe}^{2+}$ ions added in excess to reaction medium (Fedorova et al. 1999). To initiate lipid peroxidation (LPO) we add $2.5 \mathrm{mM} \mathrm{Fe}{ }^{2+}$ ions. The initial chemiluminescence burst $(\mathrm{h}, \mathrm{mV}$ ) represents the level of preexistent LPO products (reflects the stationary level of lipid hydroperoxides), the lag period of $\mathrm{Fe}^{2+}$-induced oxidation $(\tau, \mathrm{s})$ characterizes the resistance of the sample against oxidation being dependent on intrinsic antioxidant capacity of a biological sample. Chemiluminescence signal was monitored using LKB 1251 Chemiluminometer (Sweden) and was expressed in $\mathrm{mV}$ (Dobrota et al. 2005).

Measurement of malondialdehyde, 4-hydroxynonal and protein carbonyls in plasma and brain homogenates

Protein carbonyl ELISA Kit (Immundiagnostik AG cat № K7822) for the determination of protein carbonyls in biological samples was used. Principle of the test: samples containing protein reacted with dinitrophenylhydrazine (DNPH); then the non-protein constituents and unconjugated DNPH were separated by 
ultracentrifugation. The proteins were adsorbed to an ELISA plate and incubated with anti-DNPH antibodylinked horseradish peroxidase. Absorbance was related to a standard curve with oxidized serum albumin.

Malondialdehyde (MDA) ELISA Kit (Cusabio cat № CSB-E08557h) for the quantitative determination of endogenic MDA concentrations in plasma and tissue homogenates was used. Principle of the assay: the assay employs inhibition enzyme immunoassay technique. Antibody specific for MDA has been pre-coated onto a microplate. Standards and samples are pipetted into the wells with a horseradish-peroxidase (HRP) conjugated MDA. A competitive inhibition reaction between MDA (standards and samples) and HRP-conjugated MDA with the pre-coated antibody specific for MDA was launchedthe more amount of MDA in samples, then less antibody bound by HRP-conjugated MDA will bind. Following a wash to remove any unbound reagent, a substrate solution is added to the wells and color was developed. The color development was stopped and the intensity was measured.

4-hydroxynonenal (HNE) ELISA Kit (Cusabio cat № CSB-E16214h) for the quantitative determination of endogenic 4-hydroxynonenal (HNE) concentrations in plasma and tissue homogenates was used. Principle of the assay: this assay employs the quantitative sandwich enzyme immunoassay technique. Antibody specific for HNE has been pre-coated onto a microplate. Standards and samples are pipetted into the wells and any HNE present is bound by the immobilized antibody. After removing any unbound substances, a biotin-conjugated antibody specific for HNE is added to the wells. After washing, avidin HRP is added to the wells. Following a wash to remove any unbound avidin-enzyme reagent, a substrate solution is added to the wells and color develops in proportion to the amount of HNE bound in the initial step. The color development is stopped and the intensity of the color is measured.

\section{Statistical analyses}

Mean and SEM values were calculated for each parameter in each group (8 animals per experimental group). Statistically significant differences among treated group, untreated group and control groups were tested using parametric Analysis of Variance (ANOVA). Post-hoc test (Tukey-Kramer) was applied in situation where differences among groups were significant at level of significance $\alpha<0.05$. After post-hoc testing the following significance designations were specified as follows: extremely significant $(\mathrm{p}<0.001)$, highly significant $(p<0.01)$, significant $(p<0.05)$, not significant $(p>0.05)$.

\section{Results}

\section{Clinical parameters}

Body weight of animals decreased during the experiment. The most noticeable weight reduction was on day 21, when compared to healthy animals. All substances administered did not affect the change of body weight on experimental day 14 and 21 , but on day 28 TRO $(\mathrm{p}<0.01)$ increased the weight reduction caused by AA (Fig. 1B). On day 14 CARN-T $(p<0.01)$ and TRO $(\mathrm{p}<0.05)$ reduced the arthritic score of animals. On day 21 only TRO $(\mathrm{p}<0.01)$ had this effect and on day 28 all substances administered (CARN p $<0.05$, CARN-T $\mathrm{p}<0.001$ and TRO $\mathrm{p}<0.001)$ were effective in decreasing the arthritic score (Fig. 1A).

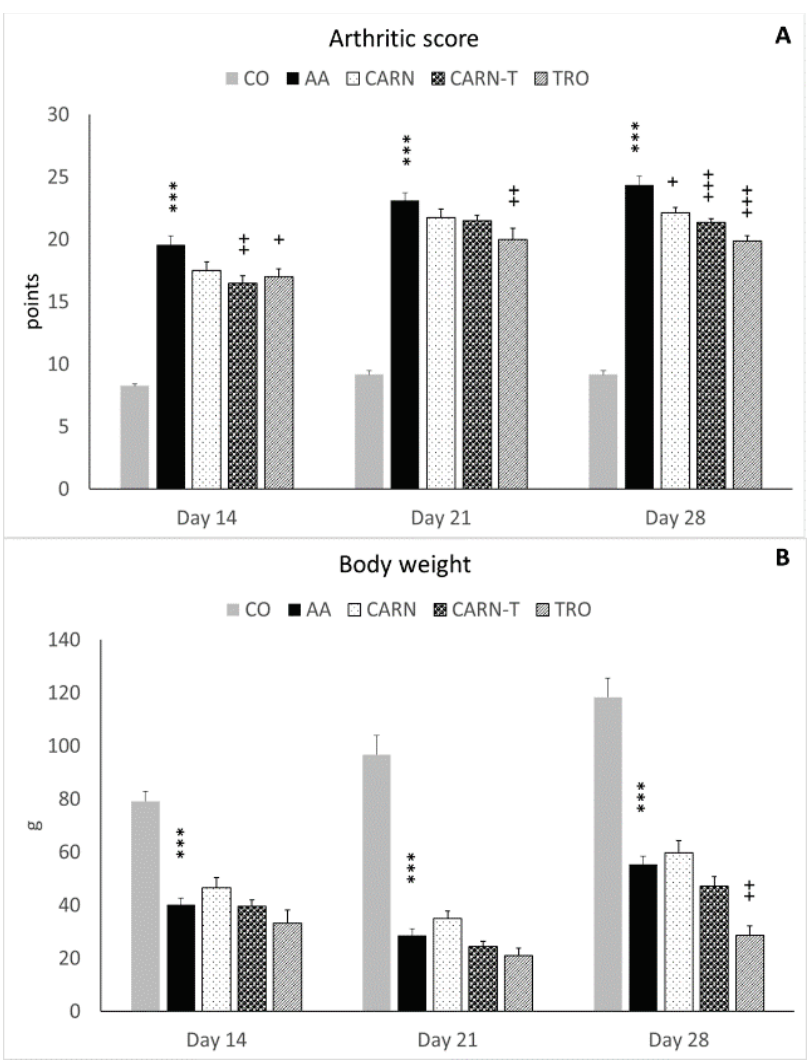

Fig. 1. Clinical parameters during adjuvant arthritis (A - Time profile of arthritic score; $\mathbf{B}-$ Change in body weight). Data are expressed as mean \pm SEM. ${ }^{* * *} \mathrm{p}<0.001$ vs. CO - healthy control, $+p<0.05$ vs. AA - adjuvant arthritis, $++p<0.01$ vs. AA, $+++\mathrm{p}<0.001$ vs. AA.

\section{Markers of inflammation in plasma on day 14}

The plasmatic level of IL- $1 \beta$ during AA on day 14 increases more than 11-times. Levels of IL-1 $\beta$ 
were significantly decreased by all substances administered $(p<0.001)$ (Fig 2A). CARN-T $(p<0.05)$ and TRO $(\mathrm{p}<0.01)$ reduced the levels of MCP-1 in plasma (Fig. 2B). Moreover CARN, CARN-T and TRO were effective in reducing the MMP-9 levels $(p<0.001)$ (Fig. 2C).

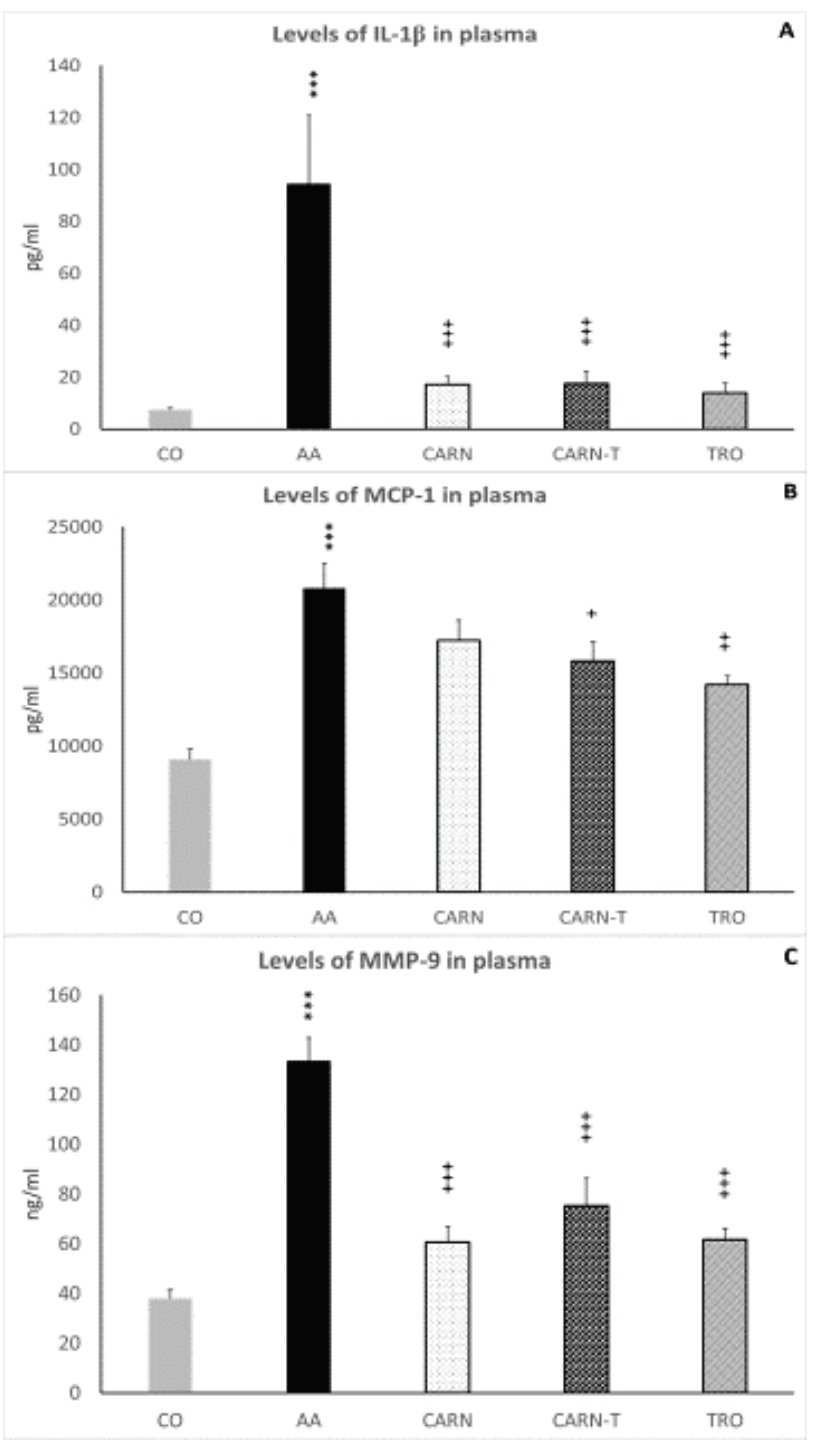

Fig. 2. Inflammatory markers measured in plasma on day 14 (A - IL-1B; B - MCP-1; C - MMP-9). Data are expressed as mean \pm SEM. *** $\mathrm{p}<0.001$ vs. CO - healthy control, $+\mathrm{p}<0.05$ vs. $A A-$ adjuvant arthritis, $++p<0.01$ vs. $A A,+++p<0.001$ vs. AA.

Markers of oxidative stress in plasma and brain tissue homogenate

Plasma: Neither the AA nor the substances administered changed the $\mathrm{Fe}^{2+}$-induced chemiluminescence signal intensity (h). However, AA significantly reduced the lag time of chemiluminescence $(\tau)$ and all the substances administered were able to effectively increase it $(\mathrm{p}<0.001)$. Oxidation of plasmatic proteins was measured as protein carbonyls. Protein carbonyls were increased by AA. CARN $(\mathrm{p}<0.01)$ and TRO $(\mathrm{p}<0.01)$ effectively decreased the protein carbonyls to control level. AA increased oxidation of lipids in plasma was detected as levels of MDA. CARN $(p<0.001)$ and CARN-T $(p<0.001)$ reduced the levels of MDA. Another marker of lipid oxidation - HNE was also increased by AA. All substances administered were able to decrease this marker to control level $(\mathrm{p}<0.001)$ (Table 1).

Brain: AA increased the $\mathrm{Fe}^{2+}$-induced chemiluminescence signal intensity (h) only slightly. CARN $(\mathrm{p}<0.05)$ and TRO $(\mathrm{p}<0.05)$ decreased significantly this signal. AA significantly reduced the lag time of chemiluminescence $(\tau)$ and all the substances administered were able to effectively increase it (CARN and CARN-T $\mathrm{p}<0.001$, TRO $\mathrm{p}<0.01$ ). Protein carbonyls were increased during AA in brain not significantly and all substances administered decreased the protein carbonyls only slightly. AA increased the oxidation of lipids (MDA) in brain 2-times. All substances administered reduced the levels of MDA to control level $(\mathrm{p}<0.001)$. HNE was also increased by AA. All substances administered were able to decrease this marker $(\mathrm{CARN} \mathrm{p}<0.01, \mathrm{CARN}-\mathrm{T}$ and TRO $\mathrm{p}<0.05)$ (Table 2).

\section{Discussion}

ROS produced during RA and AA in the course of cellular oxidative phosphorylation and by activated phagocytic cells during oxidative bursts exceed the physiological buffering capacity and result in oxidative stress. They also serve as important intracellular signaling molecules that amplify the synovial inflammatoryproliferative response (Hitchon and El-Gabalawy 2004). One approach to counteract this situation is the use of antioxidants as therapeutic agents. To verify this hypothesis we selected for treatment of adjuvant arthritis carnosine (an effective natural endogenous antioxidant), its novel derivative (S)-6-hydroxy-2,5,7,8-tetramethylchroman-2-carbonyl- $\beta$-alanyl-L-histidine, which was synthesized by condensing the $\beta$-amino group of L-carnosine and the carboxyl group of a lipophilic antioxidant (S)-Trolox ${ }^{\mathrm{TM}}$ and a standard antioxidant trolox (Stvolinsky et al. 2012). Rat adjuvant arthritis (AA) is a good model for studying substances with antioxidant properties, because systemic oxidative stress is present and induces damage to many tissues (Bauerová 
et al. 2011, Gardi et al. 2015). Arthritis induced in rats with intradermal injection of adjuvants containing mycobacteria is an animal model often used for evaluation of potential anti-rheumatic drugs. AA in rats shares many features with human arthritis, including genetic linkage, synovial $\mathrm{CD}^{+}$cells and $\mathrm{T}$ cell dependence (Joe et al. 1999).

Table 1. Markers of oxidative stress measured in plasma on day 28.

\begin{tabular}{llllll}
\hline Plasma & \multicolumn{1}{c}{ CO } & \multicolumn{1}{c}{ AA } & \multicolumn{1}{c}{ CARN } & CARN-T & TRO \\
\hline Chemiluminescence $h(m V)$ & $62.0 \pm 2.7$ & $69.7 \pm 2.7$ & $69.8 \pm 2.0$ & $62.0 \pm 3.0$ & $64.1 \pm 1.4$ \\
Chemiluminescence lag time $\tau(s)$ & $97.14 \pm 3.42$ & $55.0 \pm 1.9^{* * *}$ & $98.33 \pm 3.8^{+++}$ & $100.8 \pm 2.44^{+++}$ & $83.3 \pm 7.15^{++}$ \\
Carbonyls $(\mu \mathrm{g} / \mathrm{ml})$ & $391.2 \pm 14.34$ & $457.72 \pm 11.09^{* *}$ & $393.36 \pm 2.21^{++}$ & $415.96 \pm 12.0$ & $391.6 \pm 15.0^{++}$ \\
$M D A(\mu \mathrm{g} / \mathrm{ml})$ & $2.4 \pm 0.39$ & $5.79 \pm 0.44^{* * *}$ & $2.9 \pm 0.25^{+++}$ & $3.52 \pm 0.2^{+++}$ & $4.58 \pm 0.17$ \\
$H N E(\mathrm{ng} / \mathrm{ml})$ & $1.54 \pm 0.16$ & $2.5 \pm 0.19^{* * *}$ & $1.5 \pm 0.07^{+++}$ & $1.45 \pm 0.06^{+++}$ & $1.1 \pm 0.11^{+++}$
\end{tabular}

Data are expressed as mean \pm SEM. $* * p<0.01$ vs. CO - healthy control, $* * * p<0.001$ vs. CO, $++p<0.01$ vs. AA - adjuvant arthritis, $+++p<0.001$ vs. AA.

Table 2. Markers of oxidative stress measured in brain on day 28.

\begin{tabular}{llllll}
\hline Brain & \multicolumn{1}{c}{ CO } & \multicolumn{1}{c}{ AA } & CARN & CARN-T & TRO \\
\hline Chemiluminescence $h(m V)$ & $73.33 \pm 1.8$ & $76.12 \pm 3.0$ & $65.6 \pm 1.8^{+}$ & $67.62 \pm 2.6$ & $66.3 \pm 1.1^{+}$ \\
Chemiluminescence lag time $\tau(s)$ & $103.33 \pm 8.1$ & $66.9 \pm 3.12^{* * *}$ & $105.7 \pm 6.3^{++}$ & $109.3 \pm 2.6^{+++}$ & $95.0 \pm 3.5^{++}$ \\
Carbonyls $(\mu \mathrm{g} / \mathrm{ml})$ & $548.07 \pm 15.0$ & $606.12 \pm 74.2$ & $475.4 \pm 10.6^{*+1}$ & $473.2 \pm 5.6$ & $470.4 \pm 10.03$ \\
$M D A(\mu \mathrm{g} / \mathrm{ml})$ & $5.38 \pm 0.73$ & $10.12 \pm 1.01^{* * *}$ & $3.45 \pm 0.23^{+++}$ & $4.95 \pm 0.28^{+++}$ & $4.8 \pm 0.43^{++}$ \\
$H N E(\mathrm{ng} / \mathrm{ml})$ & $3.26 \pm 0.17$ & $4.78 \pm 0.5^{* *}$ & $3.22 \pm 0.15^{++}$ & $3.6 \pm 0.2^{+}$ & $3.6 \pm 0.18^{+}$ \\
\hline
\end{tabular}

Data are expressed as mean $\pm \mathrm{SEM}$. $* * \mathrm{p}<0.01$ vs. CO - healthy control, $* * * \mathrm{p}<0.001$ vs. $\mathrm{CO},+\mathrm{p}<0.05$ vs. AA - adjuvant arthritis, $++p<0.01$ vs. $A A,+++p<0.001$ vs. $A A$.

For monitoring of AA progression change of body weight and arthritic score are used very often. Cachexia is present during this disease mainly due to high level of TNF- $\alpha$ (McGrath and Young 2015). On day 28 all substances administered were effective in decreasing the arthritic score. There were no significant differences among the antioxidants in reducing arthritic score. Interestingly, even if TRO decreased arthritic score, it had a cachectic effect on arthritic rats and intensified the weight loss when compared to AA. This is a first report in literature of negative activity of TRO on body weight of rats with experimental arthritis. Although, immunosuppressants used for the treatment of RA usually have a good clinical outcome, they have also many side effects. Methotrexate (MTX) has become the main immunosuppressive substance used in the treatment of patients with RA. However, the use of MTX has to be limited due to its toxic manifestations, e.g. abdominal disorder, alopecia, oral ulcers, and cytopenia (Alarcon et al. 1989). During the administration of CARN and CARN-T we did not observe side effects, thus this substances might be interesting also for patients with RA. Also our previous results report a safe use of natural substances with antioxidative properties for treatment of AA (Gardi et al. 2015, Drafi et al. 2012).

Monitoring of pro-inflammatory cytokines and chemokines is necessary for analyzing the progression of inflammatory diseases and for evaluation of the effectivity of the treatment. IL-1 $\beta$ is produced by activated macrophages as a proprotein, which is proteolytically processed to its active form by caspase- 1 and is involved in a variety of cellular activities, including cell proliferation, differentiation, apoptosis and induction of cyclooxygenase-2. A significant body of experimental evidence has implicated the proinflammatory cytokine IL-1 in the pathogenesis of RA. For example, IL-1 $\beta$ overexpression in rabbit knee joints causes arthritis with clinical and histological 
features characteristic of RA, whereas IL-1 deficiency is associated with reduced joint damage (Kay and Calabrese 2004). All substances administered decreased the IL-1 $\beta$ to basal level. It is possible that CARN and CARN-T are affecting the function of macrophages (main producers of IL-1 $\beta$ ). Expression of MCP-1 has been detected in a number of pathologic conditions associated with monocyte aggregation, including atherosclerosis, arthritis, and glomerulonephritis (Rollins 1996). The synovial fluid (SF) and serum MCP-1 concentrations are significantly higher in RA patients. Increased SF over serum concentrations suggest that MCP-1 is mainly produced locally by activated cells where it may exacerbate and sustain inflammation by attracting proinflammatory leukocytes, predominantly monocytes (Stankovic et al. 2009). Substances that can suppress the production of MCP-1 have shown beneficial effect in animal models of arthritis (Guglielmotti et al. 2000, Inoue et al. 2001). On day 14 CARN-T and TRO, but not CARN, significantly decreased the levels of MCP-1. It seems that addition of trolox molecule to CARN increases its ability to reduce MCP-1 during AA development. MMP-9 plays several important functions within neutrophil action, such as degrading extracellular matrix, activation of IL-1 $\beta$, and cleavage of several chemokines. MMP-9 was found elevated in patients sera and SF and could be referred as good laboratory marker for RA (Gruber et al. 1996). Our experimental substances were all effective in reducing this marker. This ability of antioxidants tested might be also involved in the reduction of IL-1 $\beta$ to basal values. Unfortunately the arthritic score and body weight of animals for CARN and CARN-T do not correspond well with the intensive decrease of IL- $1 \beta$ plasmatic levels on day 14 . However, not only IL- $1 \beta$, but also TNF- $\alpha$ and IL-6 play an important role in joint inflammation and swelling (Choy and Panayi 2001).

Increased oxidative stress during RA (Hitchon and El-Gabalawy 2004, Chandankhede and Gupta 2013) and in animal models of RA (Wruck et al. 2011, Bauerova et al. 2015, Gardi et al. 2015) is well documented. Our present results support these findings. AA in plasma significantly increased the lag time of chemiluminescence, protein carbonyls, MDA and HNE levels. CARN, CARN-T and also TRO protected the proteins and lipids in plasma against oxidation and confirmed as good antioxidants. There are only few information about oxidative stress and brain damage in the literature (Skurlova et al. 2010, 2011). For the first time we evidenced increased HNE, protein carbonyls and reduced lag time of chemiluminescence in rat brain during AA. Although RA is not a typical CNS involvement disease, brain dysfunctions occur in 20 to $30 \%$ of rheumatic patients. Sickness behavior may vary from neurological disorders and psychosis to headaches, mood changes and cognitive deficits (Appenzeller et al. 2004). Depression and anxiety correlate with plasma levels of C-reactive protein (CRP), suggesting that brain dysfunction is related to overactivation of the immune system and not only to pain associated with the disease (Kojima et al. 2009). AA displays various neuroendocrine, immune and behavioral changes even in its early phase: peak levels of pro-inflammatory cytokines and enhanced C-reactive protein (CRP) in plasma have been described on day 1 of the disease (Philippe et al. 1997), and enhanced production of NO radical on day 3 (Ling and Jamali 2005). In the hippocampus, upregulation of mRNA for IL-1 $\beta$, IL-6, and markers of oxidative stress-inducible NO synthase iNOS and NADPH oxidase-1 were observed within four days. The changes correlated with anxiety-like behavior (Skurlova et al. 2011). All antioxidants studied showed also neuroprotective ability and prevented lipid oxidation and decrease of lag time of chemiluminescence in brain.

In conclusion, our results underlined the importance of oxidative stress in brain during AA. CARN, CARN-T and TRO have shown good neuroprotective ability particularly against lipid oxidation. These substances might be beneficial also for arthritic patients in preventing mood changes, cognitive deficits and depression. Antioxidants administered also alleviated the clinical signs of AA (arthritic score). CARN and CARN-T caused no weight reduction like TRO that has an advantage in inflammatory arthritis.

\section{Conflict of Interest}

There is no conflict of interest.

\section{Acknowledgements}

This work was supported by grant from VEGA 2/0044/15 and bilateral SAS-RAMS project 2013-2015 coordinated by Dr. Bauerova (Slovakia) and Dr. Fedorova (Russia). 


\section{References}

ALARCON GS, TRACY IC, BLACKBURN WD JR: Methotrexate in rheumatoid arthritis. Toxic effects as the major factor in limiting long-term treatment. Arthritis Rheum 32: 671-676, 1989.

ALDINI G, CARINI M, BERETTA G, BRADAMANTE S, FACINO RM: Carnosine as a quencher of 4-hydroxynonenal: through what mechanism of reaction? Biochem Biophys Res Commun 298: 699-706, 2002.

APPENZELLER S, BERTOLO MB, COSTALLAT LT: Cognitive impairment in rheumatoid arthritis. Methods Find Exp Clin Pharmacol 5: 339-343, 2004.

BAUEROVA K, PONIST S, KUNCIROVA V, MIHALOVA D, PAULOVICOVA E, VOLPI N: Chondroitin sulfate effect on induced arthritis in rats. Osteoarthr Cartil 19: 1373-1379, 2011 a.

BAUEROVÁ K, PONIŠT S, MIHALOVÁ D, DRÁFI F, KUNCÍROVÁ V: Utilization of adjuvant arthritis model for evaluation of new approaches in rheumatoid arthritis therapy focused on regulation of immune processes and oxidative stress. Interdiscip Toxicol 4: 33-39, 2011 b.

BAUEROVA K, ACQUAVIVA A, PONIST S, GARDI C, VECCHIO D, DRAFI F, AREZZINI B, BEZAKOVA L, KUNCIROVA V, MIHALOVA D, NOSAL R: Markers of inflammation and oxidative stress studied in adjuvant-induced arthritis in the rat on systemic and local level affected by pinosylvin and methotrexate and their combination. Autoimmunity 48: 46-56, 2015.

BOLDYREV AA: Retrospectives and perspectives on the biological activity of histidine-containing dipeptides. Int $J$ Biochem 22: 129-132, 1990.

BOLDYREV AA, SEVERIN SE: The histidine-containing dipeptides, carnosine, and anserine: distribution, properties, and biological significance. Adv Enzyme Reg 30: 175-193, 1990.

CHANDANKHEDE MS, GUPTA MM: Oxidative stress and antioxidant status in patients with rheumatoid arthritis. Int J Biol Med Res 4: 3088-3090, 2013.

CHOY EH, PANAYI GS: Cytokine pathways and joint inflammation in rheumatoid arthritis. $N$ Engl J Med 344: 907-916, 2001.

DOBROTA D, FEDOROVA T, STVOLINSKY S, BABUSHIKOVA E, LIKAVCANOVA K, DRGOVA A, STRAPKOVA A, BOLDYREV A: Carnosine protects the brain of rats and mongolian gerbils against ischemic injury: after-stroke-effect. Neurochem Res 30: 1283-1288, 2005.

DRAFI F, BAUEROVA K, VALACHOVA K, PONIST S, MIHALOVA D, JURANEK I: Carnosine inhibits degradation of hyaluronan induced by free radical processes in vitro and improves the redox imbalance in adjuvant arthritis in vivo. Neuro Endocrinol Lett 31: 96-100, 2010.

DRAFI F, BAUEROVA K, KUNCIROVA V, PONIST S, MIHALOVA D, FEDOROVA T, HARMATHA J, NOSAL R: Pharmacological influence on processes of adjuvant arthritis: Effect of the combination of an antioxidant active substance with methotrexate. Interdiscip Toxicol 5: 84-91, 2012.

FEDOROVA TN, BOLDYREV AA, GANNUSHKINA IV: Lipid peroxidation in experimental ischemia of the brain. Biochemistry (Moscow) 64: 75-79, 1999.

GARDI C, BAUEROVA K, STRINGA B, KUNCIROVA V, SLOVAK L, PONIST S, DRAFI F, BEZAKOVA L, TEDESCO I, ACQUAVIVA A, BILOTTO S, RUSSO GL: Quercetin reduced inflammation and increased antioxidant defense in rat adjuvant arthritis. Arch Biochem Biophys 583: 150-157, 2015.

GRUBER BL, SORBI D, FRENCH DL, MARCHESE MJ, NUOVO GJ, KEW RR, ARBEIT LA: Markedly elevated serum MMP-9 (gelatinase B) levels in rheumatoid arthritis: a potentially useful laboratory marker. Clin Immunol Immunopathol 78: 161-171, 1996.

GUGLIELMOTTI A, D'ONOFRIO E, COLETTA I, AQUILINI L, MILANESE C, PINZA M: Amelioration of rat adjuvant arthritis by therapeutic treatment with bindarit, an inhibitor of MCP-1 and TNF-alpha production. Inflamm Res 51: 252-258, 2000.

HIPKISS A, BROWNSON C: Carnosine reacts with protein carbonyl groups: another possible role for the anti-ageing peptide? Biogerontology 1: 217-223, 2000.

HITCHON CA, EL-GABALAWY HS: Oxidation in rheumatoid arthritis. Arthritis Res Ther 6: 265-278, 2004. 
INOUE T, YAMASHITA M, HIGAKI M: The new antirheumatic drug KE-298 suppresses monocyte chemoattractant protein (MCP)-1 and RANTES production in rats with adjuvant-induced arthritis and in IL-1beta-stimulated synoviocytes of patients with rheumatoid arthritis. Rheumatol Int 20: 149-153, 2001.

JOE B, GRIFFITHS MM, REMMERS EF, WILDER RL: Animal models of rheumatoid arthritis and related inflammation. Curr Rheumatol Rep 1: 139-148, 1999.

KAY J, CALABRESE L: The role of interleukin-1 in the pathogenesis of rheumatoid arthritis. Rheumatology (Oxford) 43: iii2-iii9, 2004.

KOJIMA M, KOJIMA T, SUZUKI S, OGUCHI T, OBA M, TSUCHIYA H, SUGIURA F, KANAYAMA Y, FURUKAWA TA, TOKUDOME S, ISHIGURO N: Depression, inflammation, and pain in patients with rheumatoid arthritis. Arthritis Rheum 61: 1018-1024, 2009.

KUNCIROVA V, PONIST S, MIHALOVA D, DRAFI F, NOSAL R, ACQUAVIVA A, GARDI C, HARMATHA J, HRADKOVA I, BAUEROVA K: N-feruloylserotonin in preventive combination therapy with methotrexate reduced inflammation in adjuvant arthritis. Fundam Clin Pharmacol 28: 616-626, 2014.

MCGRATH CM, YOUNG SP: Lipid and metabolic changes in rheumatoid arthritis. Curr Rheumatol Rep 17: 534, 2015.

PAVLOV AR, REVINA AA, DUPIN AM, BOLDYREV AA, YAROPOLOV AI: The mechanism of interaction of carnosine with superoxide radicals in water solutions. Biochim Biophys Acta 1157: 304-312, 1993.

PHILIPPE P, GEGOUT-POTTIE C, GUINCAMP K, BORDJI B, TERLAIN P, NETTER, P, GILLET P: Relations between functional, inflammatory, and degenerative parameters during adjuvant arthritis in rats. Am J Physiol 273: R1550-R1556, 1997.

ROLLINS BJ: Monocyte chemoattractant protein 1: a potential regulator of monocyte recruitment in inflammatory disease. Mol Med Today 2: 198-204, 1996.

RUBTSOV AM, SCHARA M, SENTJURC M, BOLDYREV A: Hydroxyl radical-scavenging activity of carnosine: a spin trapping study. Acta Pharm Jugosl 41: 401-407, 1991.

SKURLOVA M, STOFKOVA A, KISS A, BELACEK J, PECHA O, DEYKUN K, JURCOVICOVA J: Transient anorexia, hyper-nociception and cognitive impairment in early adjuvant arthritis in rats. Endocr Regul 44: 165-173, 2010.

SKURLOVA M, STOFKOVA A, JURCOVICOVA J: Anxiety-like behavior in the elevated-plus maze tests and enhanced IL-1 $\beta$, IL-6, NADPH oxidase-1, and iNOS mRNAs in the hippocampus during early stage of adjuvant arthritis in rats. Neurosci Lett 487: 250-254, 2011.

STANKOVIC A, SLAVIC V, STAMENKOVIC B, KAMENOV B, BOJANOVIC M, MITROVIC DR: Serum and synovial fluid concentrations of CCL2 (MCP-1) chemokine in patients suffering rheumatoid arthritis and osteoarthritis reflect disease activity. Bratisl Lek Listy 110: 641-646, 2009.

STVOLINSKY SL, BULYGINA ER, FEDOROVA TN, MEGURO K, SATO T, TYULINA OV, ABE H, BOLDYREV AA: Biological activity of novel synthetic derivatives of carnosine. Cell Mol Neurobiol 30: 395-404, 2010.

STVOLINSKY S, TOROPOVA K, GORDEEVA M, KAZEY V, SATO T, MEGURO K, BOLDYREV A: Carnosine and its (S)-Trolox ${ }^{\mathrm{TM}}$ derivative protect animals against oxidative stress. Amino Acids 43: 165-170, 2012.

WRUCK CJ, FRAGOULIS A, GURZYNSKI A, BRANDENBURG LO, KAN YW, CHAN K, HASSENPFLUG J, FREITAG-WOLF S, VAROGA D, LIPPROSS S, PUFE T: Role of oxidative stress in rheumatoid arthritis: insights from the Nrf2-knockout mice. Ann Rheum Dis 70: 844-850, 2011. 